\title{
CASE STUDY ON ENHANCED LANDFILL MINING AT MONT-SAINT- GUIBERT LANDFILL IN BELGIUM: MECHANICAL PROCESSING OF FINE FRACTIONS FOR MATERIAL AND ENERGY RECOVERY
}

\section{Juan Carlos Hernández Parrodi ${ }^{13, *}$, Karoline Raulf ${ }^{2}$, Daniel Vollprecht ${ }^{1}$, Thomas Pretz ${ }^{2}$ and Roland Pomberger ${ }^{1}$}

\footnotetext{
${ }^{1}$ Montanuniversität Leoben, Department of Environmental and Energy Process Engineering, 8700 Leoben, Austria

${ }^{2}$ RWTH Aachen University, Department of Processing and Recycling, 52062 Aachen, Germany

${ }^{3}$ Renewi Belgium SA/NV, NEW-MINE project, 3920 Lommel, Belgium
}

Article Info:
Received:
13 September 2019
Revised:
27 November 2019
Accepted:
6 December 2019
Available online:
23 December 2019
Keywords:
Enhanced landfill mining
Mechanical processing
Secondary raw materials
Material recovery
Energy recovery
Fine fractions

Article Info:

13 September 2019

Revised:

Accepted:

23 December 201

Enhanced landfill mining

Mechanical processing

Material recovery

Fine fractions

\begin{abstract}
(Enhanced) landfill mining ((E)LFM) projects have been mainly driven by land reclamation, environmental pollution mitigation and remediation of old landfills and dumpsites, among others. However, previous studies have also shown that these sites may be a relevant source of secondary raw materials. In this respect and within the framework of the "EU Training Network for Resource Recovery through Enhanced Landfill Mining - NEW-MINE", around $374 \mathrm{Mg}$ of waste was excavated from a landfill site in the municipality of Mont-Saint-Guibert, Belgium, as part of a case study to evaluate the full implementation of ELFM. The excavated landfilled material was pre-processed with a ballistic separator onsite directly after excavation, with which the fine fractions (material $<90 \mathrm{~mm}$ ) were obtained. Subsequently, samples of the fine fractions were characterized in order to determine their main properties and material composition, which in turn were used to define the material and energy recovery strategies to be followed. According to these strategies a chain of mechanical processing steps was selected and tested in the processing of the fine fractions in the optimal water content (15 wt.\% WC) and dry states. The mechanical processing consisted of particle size classification, ferrous and non-ferrous metals extraction, density separation and sensor-based sorting steps. For the recovery of materials (waste-to-material), fractions of a soil-like material (fine fractions $<4.5 \mathrm{~mm}$ ), inert, ferrous and non-ferrous metals were targeted. These fractions might be suitable for replacing soil in construction applications (e.g. embankments), substituting construction aggregates (e.g. construction gravel) and recycling, respectively. For the recovery of energy (waste-to-energy), a fraction composed of combustible materials was aimed for, which might be suitable for the production of an alternative fuel (e.g. refuse derived fuel). The mechanical processing in the dry state yielded total amounts of $41.9-43.9 \mathrm{wt} . \%$ DM fine fractions $<4.5 \mathrm{~mm}, 35.9-39.0 \mathrm{wt} . \%$ DM inert materials, 7.4-10.0 wt.\% DM combustible materials, 1.2-1.8 wt.\% DM ferrous metals and $0.2-0.4$ wt.\% DM non-ferrous metals. These figures suggest that a significant share of the fine fractions could be recovered through the tested mechanical processing approach, which might contribute to the overall economic and environmental feasibility of the project in case of implementing full scale (E)LFM at the studied landfill site.
\end{abstract}

\section{INTRODUCTION}

Early research shows that (enhanced) landfill mining ((E)LFM) projects have been mainly driven by land reclamation, environmental pollution mitigation and remediation of old landfills and dumpsites, among others (Hernández Parrodi, Höllen, \& Pomberger, 2018a). However, many LFM projects have faced strong difficulties or even failed to achieve immediate economic feasibility, which does not take into account long-term environmental passive costs, such as landfill aftercare and air, water and soil pollution remediation, among others. Furthermore, this has been frequently accompanied by social, political and legislatorial resistance, despite the pollution remediation and mitigation nature of LFM. Altogether, such circumstances have created skepticism towards the viability of the LFM concept and hampered its widespread practice. Therefore,
* Corresponding author:

Juan Carlos Hernández Parrodi

email: juan.carlos.parrodi@renewi.com 
LFM has evolved over the last decade into a sound concept known as ELFM, which seeks to meet the environmental, social and economic constraints in LFM; incorporating maximum material and energy recovery, while complying with the most stringent environmental and social criteria (Jones, Geysen, Rossy, \& Bienge, 2010). Within the framework of ELFM, a research project from the European Union started in 2016 and has been studying the full implementation of this concept. This project is the "EU Training Network for Resource Recovery through Enhanced Landfill Mining - NEW-MINE", which studies, among others, additional sources of revenue, such as high value-added products (i.e. hydrogen, methane, synthetic polymers and glass ceramics), as well as the involved social, environmental and policy implications to promote not only economic but overall feasibility of ELFM and its successful implementation in current waste management systems (Hernández Parrodi et al., 2019b).

NEW-MINE is related to a handful of landfill sites in Europe, including the Mont-Saint-Guibert (MSG) landfill in Belgium. The latter was chosen to perform the assessment of a whole case study on ELFM. Landfill waste was excavated from the MSG landfill and pre-processed onsite directly after excavation. Two ballistic separation steps were employed as pre-processing, in which the excavated material was divided into different outputs. The relevant output stream for the present study are the fine fractions, which was the material with a particle size $<90 \mathrm{~mm}$ obtained after the second step of ballistic separation. Representative single samples were taken at the underscreen outlet of the ballistic separator. Those single samples were used to prepare composite samples, which were employed to perform the material characterization of the fine fractions reported in Hernández Parrodi et al., 2019a. According to the results of the material characterization, the waste-to-material (WtM) and waste-to-energy (WtE) strategies for the fine fractions were defined and a specific mechanical processing approach was selected.

The main purpose of the selected mechanical processing was to separate the fine fractions into five different fractions: combustibles, inert, ferrous (Fe) metals, non-ferrous (non-Fe) metals and fine fractions $<4.5 \mathrm{~mm}$. Combustibles were intended to produce a fraction with high calorific value that could be used as refuse derived fuel (RDF). This type of material recovered from old landfill sites is usually very heterogenous and presents undesired characteristics for traditional recycling, such as significant water content, great amount of impurities and high state of degradation. Hence, thermo-chemical processes (i.e. incineration, gasification and pyrolysis) might result to be some of the few presently available and feasible alternatives to valorize landfill-mined materials with high calorific value, transforming them into a potential source of energy for WtE applications. Inert, Fe and Non-Fe metals, as well as the fine fractions $<4.5 \mathrm{~mm}$, targeted towards WtM. The recovery of Fe and non-Fe metals was envisaged for recycling, while the production of a substitute for construction aggregates was foreseen with the inert fraction. A substitute for soil in construction applications was targeted with the fine fractions $<4.5 \mathrm{~mm}$.
To this end, composite samples of the fine fractions from the MSG landfill were processed with a series of mechanical processing equipment. The equipment employed, as well as the results obtained are presented herein. The main objective of this study is to evaluate and discuss the performance of the selected mechanical processing approach for optimum material and energy recovery in (E)LFM.

\section{MATERIALS AND METHODS}

\subsection{Site description, excavation works and material pre-processing}

The landfill site "Centre d'enfouissement Technique de Mont-Saint-Guibert (CETeM)" is located in the municipality of MSG in Wallonia, Belgium, about $33 \mathrm{~km}$ south of Brussels capital city. This landfill was one of the main disposal sites of municipal solid waste (MSW), non-hazardous industrial waste (IW) and construction and demolition waste (C\&D) in the province of Walloon Brabant from 1958 to 2014 (Bureau d'études greisch (beg), 2002). For this investigation about $425 \mathrm{~m}^{3}(374 \mathrm{Mg})$ of landfill waste were excavated ( $\sim 10 \mathrm{~m}$ long, $\sim 10 \mathrm{~m}$ wide and $\sim 4 \mathrm{~m}$ deep) and the excavated volume was divided into four sub-volumes, which are henceforth referred to as batches. These batches were visually classified according to their main composition, as a clear stratification of the material was identified during excavation. The C\&D and MSW layers had a thickness of about $2 \mathrm{~m}$ each. Hence, the dimensions of each batch were $\sim 5 \mathrm{~m}$ in length, $\sim 5 \mathrm{~m}$ in width and either $\sim 2 \mathrm{~m}$ or $\sim 4 \mathrm{~m}$ in depth, depending on the targeted material to be excavated. Directly after excavation, each batch was pre-processed individually with a ballistic separator (Stadler model STT 6000) in two steps; first with screen paddles of $200 \mathrm{~mm}$ and subsequently with screen paddles of $90 \mathrm{~mm}$ in cascade arrangement. The fine fractions processed in this case study correspond to the underscreen fraction $<90 \mathrm{~mm}$ obtained after the second ballistic separation step. Information about the coarse fractions (material $\geq 90 \mathrm{~mm}$ ), as well as further details about the ballistic separation process have been reported by García López et al., 2019.

During the pre-processing of each batch representative single samples from the underscreen output fraction of the ballistic separator were taken, and composite samples were prepared from the single samples. This study focuses solely on the mechanical processing of the composite samples of batches 1 and 2, from which a total of 32 single samples (16 single samples for each batch) of 10 I were taken and 16 composite samples (8 composite samples for each batch) of 20 I were prepared using the quartering method, according to the German guideline for procedures for physical, chemical and biological testing in relation to the recovery/disposal of waste (LAGA PN 98).

Further information regarding the landfill site, excavation works, material pre-processing and sampling procedures are reported in Hernández Parrodi et al., 2019a. The results of all composite samples, material fractions and particle size ranges (i.e. material characterization, (optimal) water content and mechanical processing) presented herein are based on mass percentage (wt.\%), for 
which an industrial platform scale (Kern DS 150K1, resolution of $1.0 \mathrm{~g}$ ) and a precision balance (Kern KB 2400-2N, resolution of $0.01 \mathrm{~g}$ ) were employed. Water and dry mass contents were determined according to the DIN EN 14346 (modified: drying at $75^{\circ} \mathrm{C} \pm 5^{\circ} \mathrm{C}$ to avoid melting of certain plastics and material losses), while the drying processes were carried out in a Heraeus industrial drying oven.

\subsection{Fine fractions}

The material characterization of the fine fractions from the MSG landfill was performed by Hernández Parrodi et al., 2019a, who reported overall ranges for bulk density and water content of 720-1 $000 \mathrm{~kg} / \mathrm{m}^{3}$ (median of $810 \mathrm{~kg} /$ $\mathrm{m}^{3}$ ) and 25-30 wt.\% (median of $27 \mathrm{wt} . \%$ ), respectively. The data of the material composition of the fine fractions 90 $10 \mathrm{~mm}$ in dry state from that study was reclassified in 3 particle size ranges (i.e. $90-31.5 \mathrm{~mm}, 31.5-10 \mathrm{~mm}$ and Fine fractions $<10 \mathrm{~mm}$ ) and 7 grouped material fractions (i.e. "Combustibles", "Inert", "Fe metals", "Non-Fe metals", "Others", "Agglomerated fines $<10 \mathrm{~mm}$ " and "Mixed materials") in this study, in order to allow direct comparison with the results of the mechanical processing. The reclassification consisted in separating the grouped material fraction "Total metals" from the material characterization into the fractions "Fe metals" and "Non-Fe metals", as well as in joining the particle size ranges $90-63 \mathrm{~mm}$ and $63-31.5 \mathrm{~mm}$ to form a particle size range of $90-31.5 \mathrm{~mm}$. This information is shown in Table 1.

Figures in Table 1 were calculated using the $25^{\text {th }}, 50^{\text {th }}$ (median) and $75^{\text {th }}$ percentiles in order to depict the variation range of the amount of each grouped material fraction, which can be used as reference to evaluate the recovery of "Combustibles", "Inert", "Fe metals" and "Non-Fe metals"

TABLE 1: Material composition of the fine fractions in dry state (modified from Hernández Parrodi et al., 2019a).

\begin{tabular}{|c|c|c|c|c|}
\hline \multirow{2}{*}{\multicolumn{2}{|c|}{$\begin{array}{l}\text { Particle size range/Grouped } \\
\text { material fraction }\end{array}$}} & \multicolumn{3}{|c|}{ Amount [wt.\%] } \\
\hline & & \multirow{2}{*}{$\begin{array}{c}\begin{array}{c}\mathbf{2 5}^{\text {th }} \\
\text { percentile }\end{array} \\
0.9\end{array}$} & \multirow{2}{*}{$\begin{array}{c}\text { Median } \\
4.0\end{array}$} & \multirow{2}{*}{$\begin{array}{c}\mathbf{7 5}^{\text {th }} \\
\text { percentile } \\
9.9\end{array}$} \\
\hline $90-31.5$ mm & Combustibles & & & \\
\hline & Inert & 9.7 & 13.3 & 15.1 \\
\hline & Fe metals & 0.2 & 0.3 & 0.7 \\
\hline & Non-Fe metals & 0.0 & 0.2 & 0.5 \\
\hline & Others & 0.0 & 0.2 & 1.9 \\
\hline & $\begin{array}{l}\text { Agglomerated } \\
\text { fines }<10 \mathrm{~mm}\end{array}$ & 0.2 & 0.3 & 0.4 \\
\hline \multirow[t]{6}{*}{$31.5-10 \mathrm{~mm}$} & Combustibles & 1.3 & 3.7 & 9.6 \\
\hline & Inert & 17.8 & 19.9 & 22.2 \\
\hline & Fe metals & 0.2 & 0.3 & 0.5 \\
\hline & Non-Fe metals & 0.1 & 0.1 & 0.2 \\
\hline & Others & 0.4 & 0.6 & 1.1 \\
\hline & $\begin{array}{l}\text { Agglomerated } \\
\text { fines }<10 \mathrm{~mm}\end{array}$ & 2.9 & 3.5 & 3.8 \\
\hline $\begin{array}{l}\text { Fine fractions } \\
<10 \mathrm{~mm}\end{array}$ & Mixed materials & 37.8 & 51.8 & 55.6 \\
\hline
\end{tabular}

Notes: Total amounts do not account for 100 wt.\% due to the utilization of quantiles. from the fine fractions of the MSG landfill in the tested mechanical processing. These figures show that median amounts of about 4.0 wt.\% "Combustibles", 13.3 wt.\% "Inert", 0.3 wt.\% "Fe metals" and 0.2 wt.\% "Non-Fe metals" could be recovered from particle size range $90-31.5 \mathrm{~mm}$, while around 3.7 wt.\% "Combustibles", 19.9 wt.\% "Inert", 0.3 wt.\% "Fe metals" and 0.1 wt.\% "Non-Fe metals" could be obtained from particle size range $31.5-10 \mathrm{~mm}$. Additionally, about half of the total amount of the fine fractions (median of $51.8 \mathrm{wt} . \%$ ) can be expected to be $<10 \mathrm{~mm}$.

\subsection{Particle size distribution and water content}

A study on the particle size distribution of the fine fractions from batches 1 and 2 with different water contents was carried out in order to identify the optimal water content. The optimal water content is that with which the fine fractions are still able to be handled efficiently in a dry mechanical process without the need of complete drying. Theoretically, less resources (i.e. energy and time) would be needed to reach adequate mechanical processing in this way, while material losses and dust generation would be decreased significantly. Eight composite samples of batch $1(n=4)$ and batch $2(n=4)$ were used to determine the range of the particle size distribution with water contents of $10 \mathrm{wt} . \%$ and $20 \mathrm{wt} . \%$, respectively. Initially all composite samples were dried completely according to the DIN EN 14346 (as described in Section 2.1) and, subsequently, the corresponding water contents were set following the procedure described in Section 2.4.1. Afterwards, the composite samples were sieved in a circular vibratory box sieve (Siebtechnik, $500 \mathrm{~mm} \times 500 \mathrm{~mm}$ ) with circular reticle sieves of $63 \mathrm{~mm}, 31.5 \mathrm{~mm}$ and $10.0 \mathrm{~mm}$, followed by a sieving with a circular vibratory sieve tower (Siebtechnik, $\varnothing 400 \mathrm{~mm}$ ) with squared reticle sieves of $6.3 \mathrm{~mm}, 3.15 \mathrm{~mm}$, $1.0 \mathrm{~mm}, 0.63 \mathrm{~mm}, 0.315 \mathrm{~mm}$ and $0.16 \mathrm{~mm}$, according to the DIN EN 15415-1:2011. Finally, the obtained curves were compared to the particle size distribution ranges from both batches in raw $(n=8)$ and dry $(n=8)$ states from the material characterization (Hernández Parrodi et al., 2019a) in order to identify the optimal water content.

\subsection{Mechanical processing}

A specific process chain of mechanical equipment was selected to process the fine fractions according to the results of the material characterization and the defined strategies for WtM and WtE reported in Hernández Parrodi et al., 2019a. This arrangement was selected with the main objective of optimizing the recovery of certain fractions from the fine fractions; such as a fraction with high calorific value that could be used as an alternative fuel (e.g. RDF/Solid Recovered Fuel (SRF)), an inert fraction that could be used as substitute for construction aggregates (e.g. construction sand/gravel) and a soil-like fraction (i.e. fine fractions $<4.5 \mathrm{~mm}$ ) that could be used as substitute for soil in construction applications (e.g. dykes/ embankments), as well as fractions composed of Fe and non-Fe metals that could be recycled. At the same time, the selected arrangement aims at reducing the amount of the fine fractions to be re-landfilled or stored until more adequate technologies are developed for its valorization 
or further utilization. To this end, a dry mechanical processing approach was chosen, since wet processing methods tend to be more elaborate and complex, and have been associated with higher capital and operational costs in the past (Bunge, 2012). Additionally, wet methods involve sending a certain share of impurities and contaminants to an aqueous medium, which must be treated at some point as well. Furthermore, in the context of (E)LFM most of the outputs of a wet processing approach will need a significant reduction in moisture before being suitable for WtM and WtE schemes.

Figure 1 presents an overview of the mechanical processing approach implemented in this study. The whole mechanical processing was investigated using composite samples of batches 1 and 2 in the optimal water content state $(n=8)$ and in the dry state $(n=8)$, in which 4 composite samples of each batch were processed in the optimal water content state and 4 composite samples in the dry state. Each composite sample was processed individually in order to study the variation between samples as well. Figure 1 shows two main material flows (black arrows): one for the composite samples in the optimal water content state and one for those in the dry state.

In order to avoid further alteration of the composite samples (e.g. moisture gain/loss, material loss, weathering and fractionation), the calibration of all processing equipment, except for the sensor-based sorter, was performed by means of artificial samples, which were composed of similar type of materials in new state (i.e. hard and soft plastics, paper, wood, glass, stones, metals and soil) and prepared in such a way that the main characteristics of the material (i.e. composition, density, particle size range and water content) were simulated. The sensor-based sorting equipment was calibrated with real representative pieces of each material type selected by hand, since the actual spectra of each material were needed for the calibration of the equipment.

Most of the materials with high calorific value (e.g. plastics, textiles, leather, paper and wood) were expected to be found in the light fractions and, hence, a fraction called "Combustibles", which is marked in purple in Figure 1, was generated with those materials to produce an alternative fuel, which might be suitable for thermal valorization. To this end, thermogravimetry has proven to be a promising method to determine the composition of such materials and study their decomposition in thermo-chemical conversion processes, such as incineration, pyrolysis and gasification, and, thus, can be helpful for selecting the most appropriate option to be employed (Burlakovs et al., 2019). Inert materials (e.g. bricks, concrete, stones, glass and ceramics) were anticipated in the heavy fractions and, thus, a fraction denominated "Inert", which is marked in grey in Figure 1, was generated with these fractions in order to produce a substitute for construction aggregates. In addition, seashells, which are not scarce in Belgian MSW, were sorted out of the "Inert" fraction by means of sensor-based sorting and were incorporated in the "Combustibles" fraction, since they have proven to act as an effective antichlor agent (Tameda et al., 2018) due to their high calcium carbonate content. Fe and non-Fe metals, which are

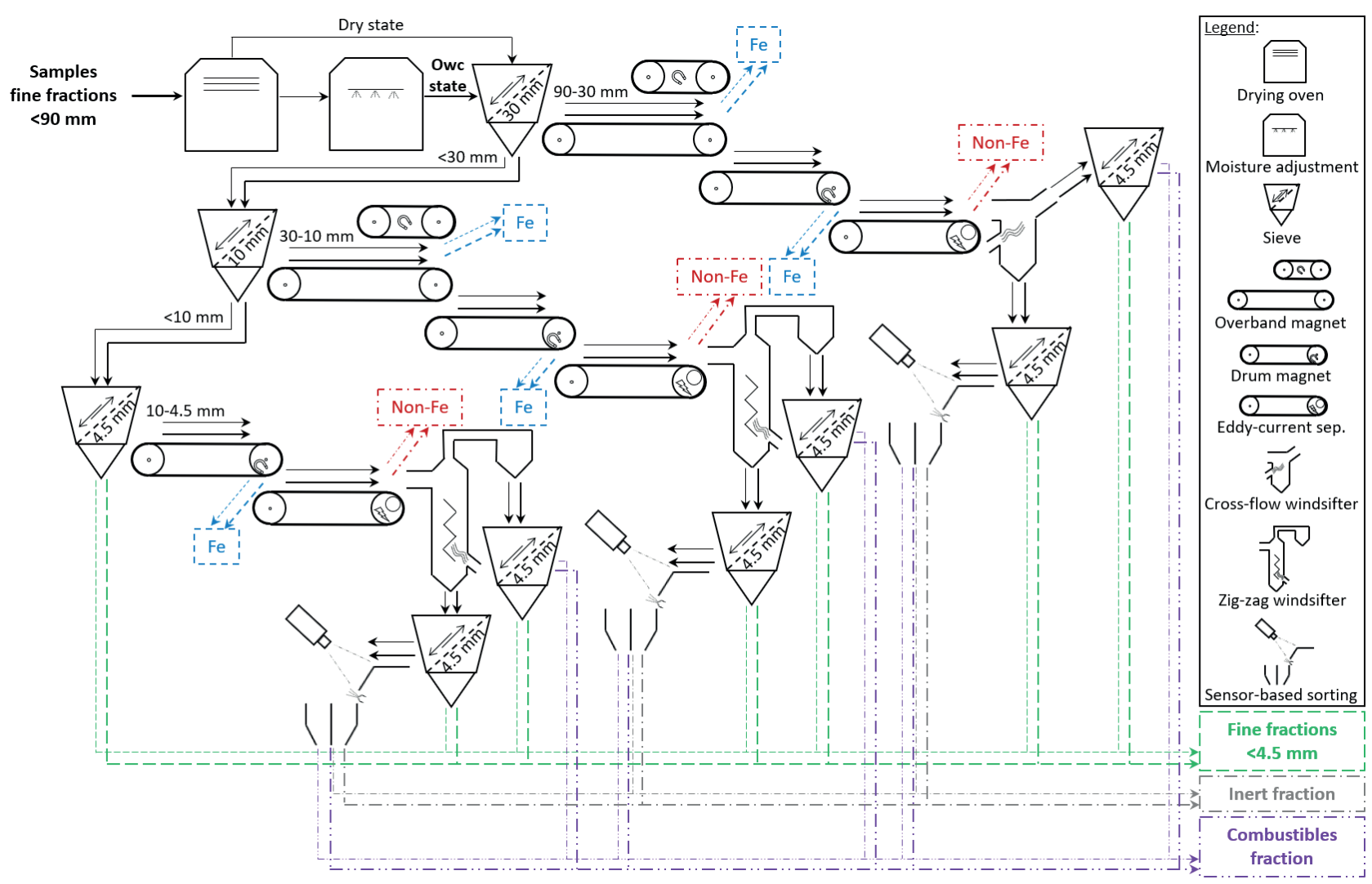

FIGURE 1: Mechanical processing flow chart of the fine fractions in the optimal water content (owc) and dry states. 
respectively marked in blue and red in Figure 1, were also extracted from the fine fractions, since they can represent a substantial share of the revenues from LFM (Van Vossen \& Prent, 2011; Winterstetter, Laner, Rechberger, \& Fellner, 2015). The results on the quality assessment of the recovered non-Fe metals for recycling purposes are reported in Lucas et al., 2019. However, the recovery of ferrous metals from landfilled material is nowadays regarded as technically possible, since it has been successfully performed in previous LFM investigations (Van Vossen \& Prent, 2011; Wagner \& Raymond, 2015). Hence, the quality of the extracted ferrous metals was not investigated in the present case study.

Additionally, a fraction named "Fine fractions $<4.5 \mathrm{~mm}$ ", which is marked in green in Figure 1, was created with the recovered surface defilements and agglomerates liberated by the coarser particle size ranges (i.e. $90-30 \mathrm{~mm}$, $30-10 \mathrm{~mm}$ and $10-4.5 \mathrm{~mm}$ ) along the mechanical processing, as well as with the underscreen fraction from the sieving step at $4.5 \mathrm{~mm}$. The properties of the "Fine fractions $<4.5 \mathrm{~mm}$ " will be studied in order to determine if a substitute for soil in construction applications could be produced with the whole or a certain amount of this fraction.

The mechanical processing until sieving steps at $4.5 \mathrm{~mm}$ was carried out at the technical facilities of the Department of Processing and Recycling (IAR) of the RWTH Aachen University, whereas the sensor-based sorting steps were performed at the technical laboratory of the Chair of Waste Processing Technology and Waste Management (AVAW) of the Montanuniversität Leoben. For explanatory purposes, the mechanical processing was organized in five stages: i) material conditioning, ii) particle size classification, iii) extraction of Fe and non-Fe metals, iv) separation of light and heavy fractions and $v$ ) quality improvement of light and heavy fractions. These stages are described in the following sections of this chapter.

\subsubsection{Material conditioning}

There are several industrial options for drying or reducing the water content of landfill-mined material, such as aeration pile, biodrying and drum furnace, among others. Each of those options has its own advantages, limitations and cost implications towards (E)LFM, which can be very relevant and, thus, must be carefully assessed beforehand. However, the drying process is not the main focus of the present study and, therefore, it is not discussed further on.

In order to set the target water contents (i.e. optimal water content state and dry state) for the 2 scenarios of the mechanical processing, the composite samples of both batches were completely dried in the industrial drying oven according to the DIN EN 14346 (as described in Section 2.1). Subsequently, water was added to half of the composite samples $(n=4)$ of each batch until the optimal water content was reached. For this, tap water was gradually and uniformly sprinkled in layers of about $3 \mathrm{~cm}$ with a manual pressurized water sprayer (GLORIA prima $3 \mathrm{I}-3 \mathrm{bar}$ ) in a 90 I container. The material was thoroughly mixed and was left to rest for $24 \mathrm{~h}$, in such a way that the water addition was evenly distributed throughout the whole sample. The remaining half of the composite samples $(n=4)$ of each batch was kept in dry state.

After setting the target water contents, the mechanical processing was conducted separately for the two groups of samples: i) composite samples $(n=8)$ in the optimal water content state and ii) composite samples $(n=8)$ in the dry state. Both groups of samples included composite samples of each batch $(n=4)$ and, from this point on, all composite samples were processed identically.

\subsubsection{Particle size classification}

Directly after the adjustment of water content the composite samples were classified into the following 4 particle size ranges:

$$
\begin{aligned}
& 90-30 \mathrm{~mm} \\
& 30-10 \mathrm{~mm} \\
& 10-4.5 \mathrm{~mm} \\
& <4.5 \mathrm{~mm}
\end{aligned}
$$

The previous particle size ranges were selected according to the results of the material characterization reported in Hernández Parrodi et al., 2019a, targeting a minimum amount of sieving steps and a maximum amount of recoverable material per particle size range. This particle size classification was done using two different types of sieves for waste materials.

The first sieving step was performed with a circular motion vibrating sieve for waste materials (iFE waste screen for waste treatment and recycling) with $30 \mathrm{~mm}$ squared sieve panels (Figure 2a). This type of sieve was used due to its vibrating circular motion operating principle, robustness and cascade arrangement of the screening panels, which make it adequate for sieving heterogeneous humid waste mixtures with minimum clogging. This equipment had a total sieving length of $2.0 \mathrm{~m}$ and width of $0.8 \mathrm{~m}$ and was operated with a fixed inclination of $15^{\circ}$. As it is shown in Figure $2 \mathrm{a}$, the sieve was feed by means of a $5.0 \mathrm{~m}$ long conveyor belt with a slope of $42^{\circ}$. The median throughput was ca. $13 \mathrm{~kg}$ (1 composite sample) per run, for which around 1 minute processing time was needed in the optimal water content state. In the dry state ca. $11 \mathrm{~kg}$ (median) was processed using the same duration.

The second and third sieving steps were done with a flip-flow type of sieve (Hein Lehmann LIWELL $®$ screening machine) with $10 \mathrm{~mm}$ and $4.5 \mathrm{~mm}$ squared screen mats, respectively (Figure $2 b$ ). A flip-flow sieve was selected as it can cope with materials difficult to sieve due to their small grain size, moist and/or sticky nature, which is the case for the fine fractions from (E)LFM. This equipment uses flexible screen mats to apply a trampoline-like movement that prevents the sieve from clogging, while breaking apart material agglomerates and sieving the input material in a uniform and continuous manner. The sieve had total functional length and width of about $3.0 \mathrm{~m}$ and $0.5 \mathrm{~m}$, respectively, and was operated with an inclination of $25^{\circ}$. In the second sieving step ca. $10 \mathrm{~kg}$ (median) of material was sieved at $10 \mathrm{~mm}$ for 1 minute per composite sample in the optimal water content state, whereas ca. $8 \mathrm{~kg}$ (median) was sieved in the dry state. In the third sieving step 

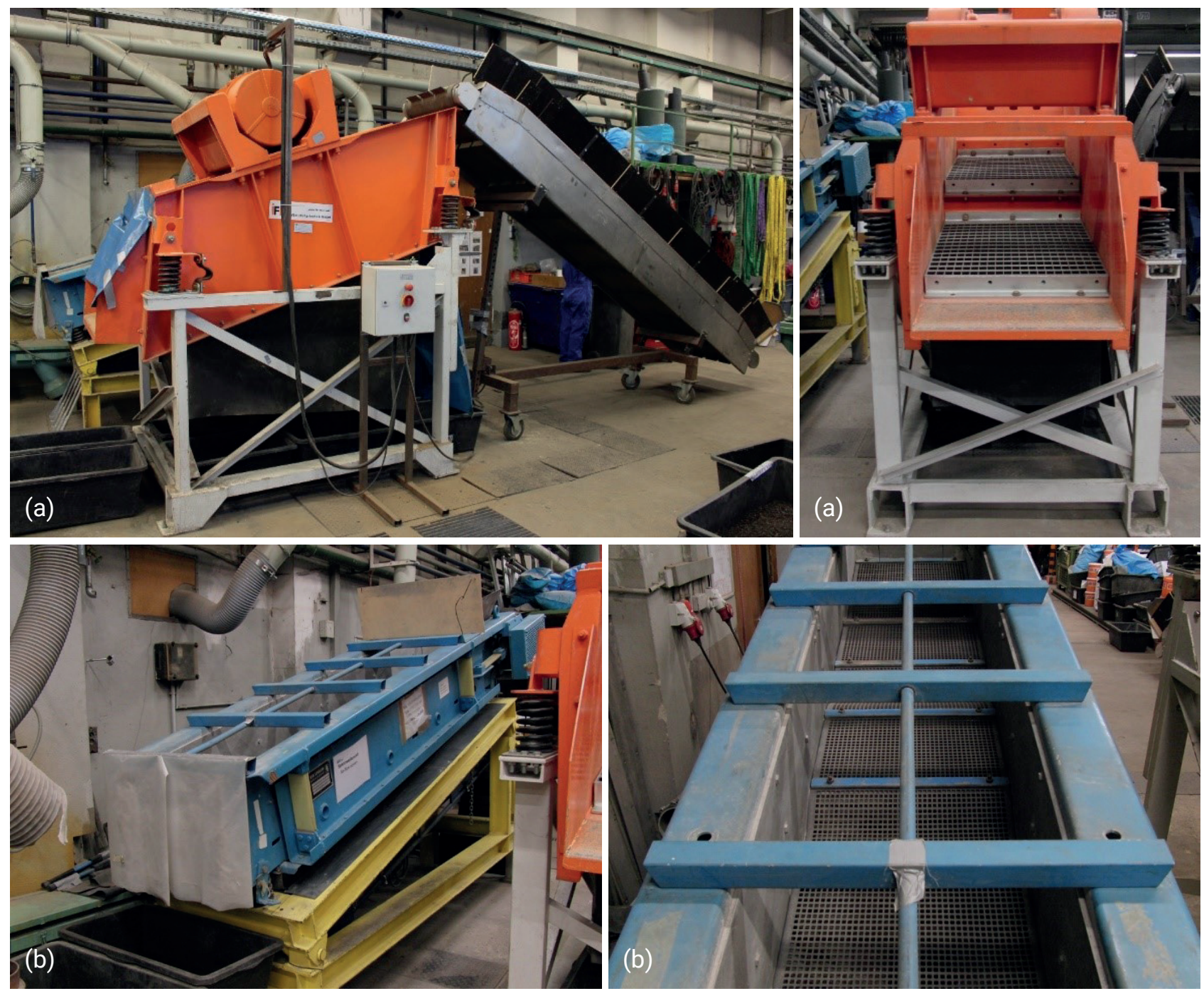

FIGURE 2: a) Circular motion vibrating and b) flip-flow sieves.

ca. $7 \mathrm{~kg}$ (median) of material was sieved at $4.5 \mathrm{~mm}$ for 1 minute in the optimal water content state and ca. $6 \mathrm{~kg}$ (median) in the dry state.

\subsubsection{Extraction of Fe and non-Fe metals}

Fe and non-Fe metals were removed by magnetic and eddy-current separators. Fe metals were extracted using an overband magnet (Figure 3a) followed by a drum magnet (Figure $3 b$ ), in a cascade arrangement, in particle size ranges $90-30 \mathrm{~mm}$ and $30-10 \mathrm{~mm}$, while they were removed employing only the drum magnet in the particle size range 10-4.5 mm. The overband magnet was used to extract the largest particles of the Fe metals fraction with high quality (low content of impurities), as the magnet was located above the throughput flow and pulled Fe metals out of the stream. In turn, the drum magnet was located below the throughput flow and pulled Fe metals out of the stream downwards. Thus, the drum magnet was used to remove the remainder of Fe metals, which ranged from Fe metal pieces attached to other materials to the smallest Fe particles (incl. iron filings and iron oxides) present in the throughput, and which normally have a poor quality. Additionally, the drum magnet was employed to protect subsequent processing equipment, i.e. eddy-current separator, since the presence of Fe metals can lead to overheating and malfunction of such equipment.

The employed overband magnet was a permanent Steinert suspension magnet ( $750 \mathrm{~mm}$ long and $100 \mathrm{~mm}$ wide) placed transversely to the throughput flow. A spacing of $180 \mathrm{~mm}$ was used for the particle size range $90-30 \mathrm{~mm}$ with respect to the conveyor belt transporting the material, while one of $60 \mathrm{~mm}$ was utilized for the particle size range 30-10 $\mathrm{mm}$ in both the optimal water content and dry states. The overband magnet was operated with a constant speed of about $1.5 \mathrm{~m} / \mathrm{s}$ and the conveyor belt was set to a constant speed of around $1.0 \mathrm{~m} / \mathrm{s}$ in both states. As for the drum magnet, a permanent Steinert drum magnetic separator (300 $\mathrm{mm}$ diameter and $500 \mathrm{~mm}$ long) was utilized, which was operated in both states at $35 \mathrm{rpm}$ and fed by a vibratory conveyor at an approximate rate of $0.5 \mathrm{~kg} /$ minute.

Non-Fe metals were extracted by means of a permanent Steinert eccentric eddy-current separator $(500 \mathrm{~mm}$ diameter and $800 \mathrm{~mm}$ long) operated at $3000 \mathrm{rpm}$ with an eccentricity of $30^{\circ}$ for the particle size range $90-30 \mathrm{~mm}$, 

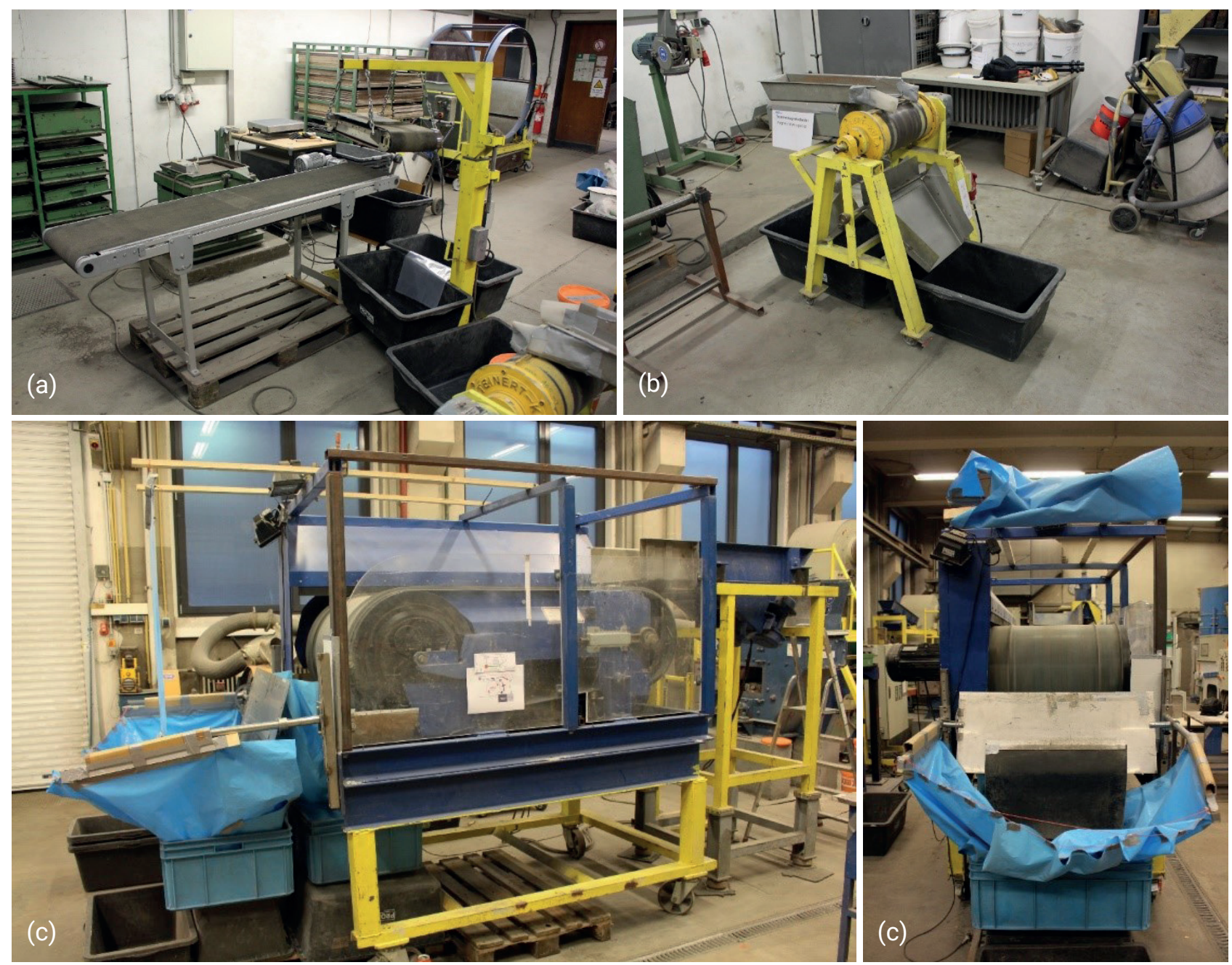

FIGURE 3: a) Overband magnetic, b) drum magnetic and c) Eddy-current separators.

$36^{\circ}$ for $30-10 \mathrm{~mm}$ and $42^{\circ}$ for $10-4.5 \mathrm{~mm}$ in both states (Figure $3 \mathrm{c}$ ). This machine was equipped with a vibratory conveyor and a conveyor belt, with which the material was driven over the eddy-current magnetic wheel at a speed of about $1.5 \mathrm{~m} / \mathrm{s}$ for all samples.

\subsubsection{Separation of light and heavy fractions}

Windsifting was used to split light from heavy materials. This density separation method uses material properties, such as density and shape to separate the throughput by means of a stream of air, which carries light materials to a different recipient.

A cross-flow windsifter (cross-flow air classifier, selfmade by the IAR) was employed to process the particle size range $90-30 \mathrm{~mm}$ (Figure $4 \mathrm{a}$ ). This equipment blows a bottom up stream of air across the throughput flow in a transversal way and light materials are transported by the air stream along a pipe to a container, while heavy materials fall down at the air stream contact area and are collected in a separate container. This equipment was utilized since it is relatively robust and can handle particle sizes up to around $200 \mathrm{~mm}$. During the operation of the cross-flow windsifter, an airflow volume flow of about $7000 \mathrm{~m}^{3} / \mathrm{h}$ was employed and the input material was delivered at a rate of around $1 \mathrm{~kg} /$ minute in both states. The fixed angle with which the air stream was injected was $45^{\circ}$ with respect to the horizontal plane.

For the processing of the particle size ranges 30 $10 \mathrm{~mm}$ and $10-4.5 \mathrm{~mm}$ a zig-zag windsifter (Graf zig-zag air classifier, custom made for the IAR) was used (Figure 4b), as it can separate small grain-sized materials with high precision. In this equipment the input material is delivered by an airtight vibratory conveyor into a horizontal zig-zag shaped channel, where an air stream is blown from bottom to top. The zig-zag shaped channel creates a combination of cross- and counter-flow air streams along multiple steps that transport light particles into an aerocyclone and subsequently to a separate recipient. The heavy fraction slides down over the zig-zag shaped channel and is collected in a container. The zig-zag windsifter was operated with an airflow speed range of 7.5-8.5 m/s for the particle size 30-10 mm, whereas 6.5-7.5 m/s was used for 10-4.5 mm in both states. The zig-zag shaped channel was around $1.2 \mathrm{~m}$ long and the input material was fed at a rate of about $0.5 \mathrm{~kg} /$ minute for the particle size range $30-10 \mathrm{~mm}$ and of $0.3 \mathrm{~kg} /$ minute for $10-4.5 \mathrm{~mm}$ in both states. 

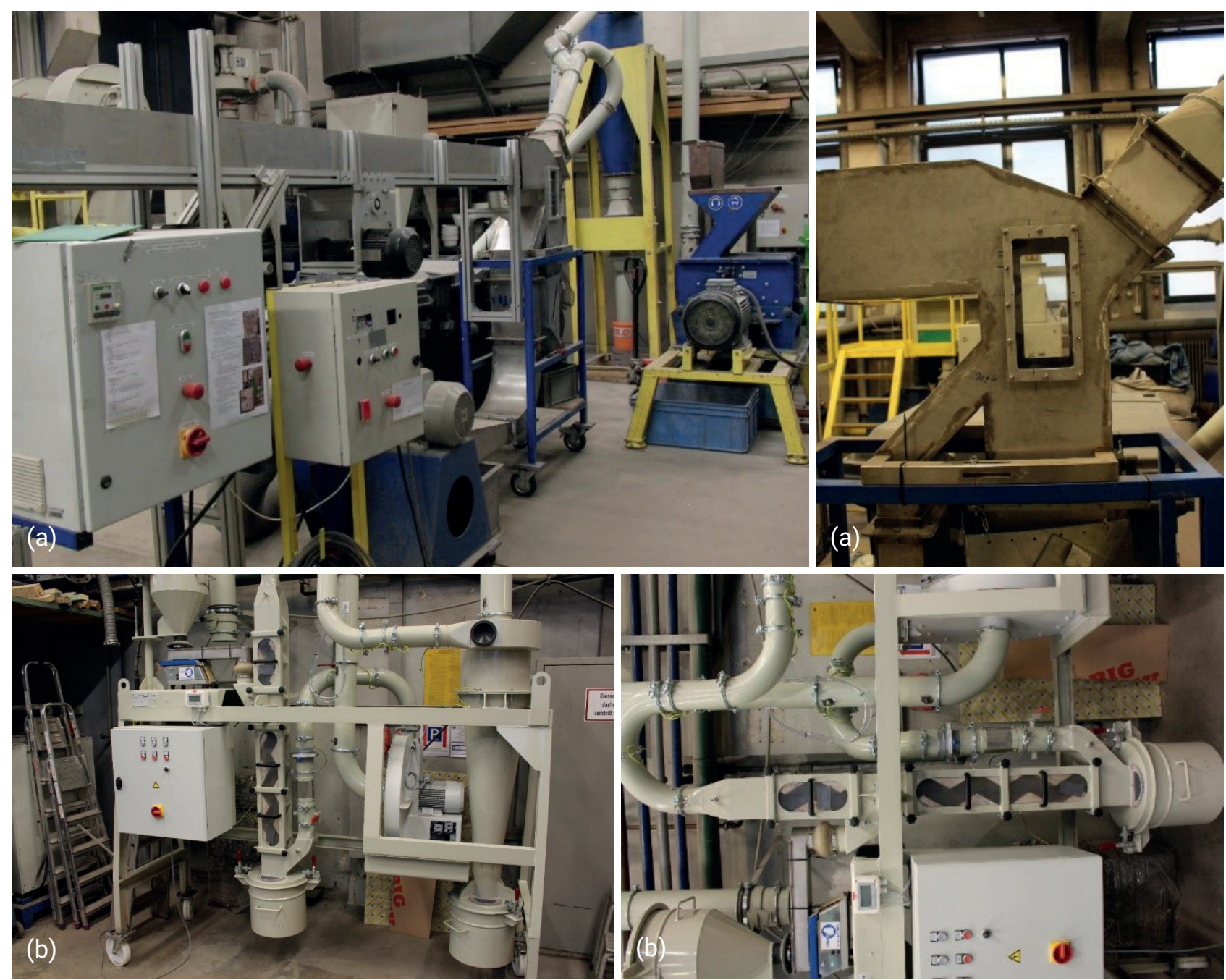

FIGURE 4: a) Cross-flow and b) zig-zag windsifters.

\subsubsection{Enrichment and quality improvement of light and he-} avy fractions

Surface defilements, agglomerates and fine particles from material weathering are loosened and released along mechanical processing. These fine materials can be removed in order to improve the quality of the output fractions. Moreover, certain combustible materials with high densities might still be found in the heavy fractions after density separation. Such materials can be removed from the heavy fraction by means of sensor-based sorting, so that the quality of the heavy fractions is improved and the amount of materials with high calorific value can be valorized together with the "Combustibles" fraction.

Light and heavy fractions from the cross-flow and zigzag windsifters were sieved further in order to remove released fine particles along the whole mechanical processing. This sieving was performed with a circular vibratory sieve tower (Siebtechnik, $\varnothing 400 \mathrm{~mm}$ ) with a squared reticle sieve of $4.5 \mathrm{~mm}$ during 1 minute in both states, since the amount of light and heavy fractions obtained from the density separation steps did not allow the employment of a larger scale equipment. Additionally, this last sieving step served the purpose of preconditioning the heavy fraction for the sensor-based sorting step, in which the presence of dust and fine particles interferes with the correct recognition and classification of the input material. The reduction of impurities in the light fraction might lead to reduce the ash content and, thus, to raise the calorific value, as well as to decrease the amount of certain contaminants, such as heavy metals and organic pollutants. Moreover, the underscreen fraction below $4.5 \mathrm{~mm}$ from the light and heavy fractions could be jointly valorized or processed further with the fraction "Fine fractions $<4.5 \mathrm{~mm}$ " in this manner.

Near infrared (NIR) was employed by the sensor-based sorter to measure the wavelength with which a certain material reflects infrared radiation. Such measurements are then used to compute the spectrum variation for each material, which is either left in the material stream or sorted out, according to the desired set up of the equipment. The sorting is done by means of a pulse of pressurized air released through a nozzle, which shoots the particles to be sorted out, sending them to a separate container. To this end, a pilot scale sensor-based sorter manufactured by binder + co with a hyperspectral imaging (HIS) chute was utilized (Figure 5), which was equipped with a vibratory conveyor. 

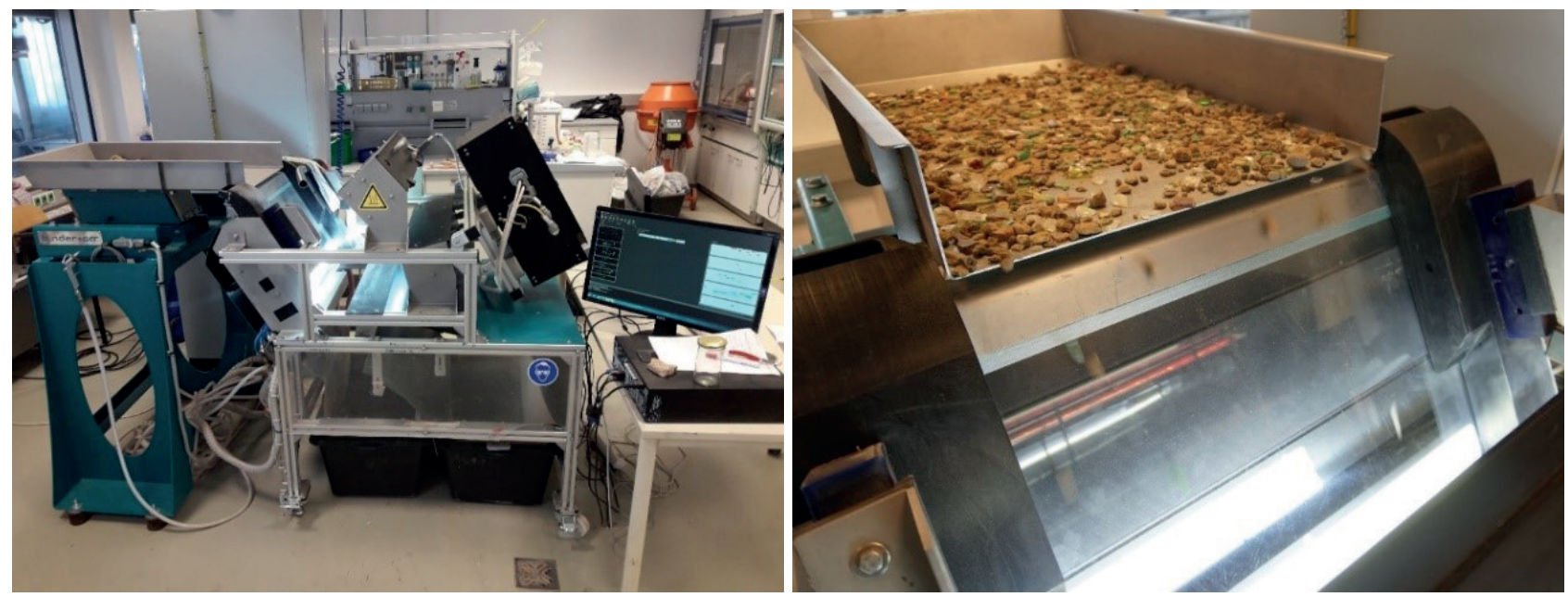

FIGURE 5: Sensor-based sorting equipment.

In this last processing step of the heavy fractions from the windsifting steps, the material was fed to the sensor recognition area at a rate of about $1 \mathrm{~kg} /$ minute, $0.5 \mathrm{~kg} / \mathrm{minu}$ te and $0.3 \mathrm{~kg} /$ minute for the particle size ranges $90-30 \mathrm{~mm}$, 30-10 $\mathrm{mm}$ and $10-4.5 \mathrm{~mm}$, respectively, in both states. The pressurized air was set to different pressures as well, which were 3 bar for $90-30 \mathrm{~mm}, 2$ bar for $30-10 \mathrm{~mm}$ and 1.5 bar for $10-4.5 \mathrm{~mm}$ in both states. Further details about this processing step are reported in Küppers, Hernández Parrodi, García López, Pomberger, \& Vollprecht, 2019.

\section{RESULTS AND DISCUSSION}

\subsection{Optimal water content}

Particle size distribution curves were calculated for the composite samples of batch 1 and batch 2 with median water contents of $0 \mathrm{wt} . \%$ (dry state), $10 \mathrm{wt} . \%, 20 \mathrm{wt} . \%$ and 27 wt.\% (raw state), and analogously as for the material composition (Section 2.2), quantiles $\left(25^{\text {th }}, 50^{\text {th }}\right.$ and $75^{\text {th }}$ percentiles) were used to determine the variation range in each water content. The particle size distribution curves (solid lines) for each water content, as well as their variation ranges (dash and dash-dot lines), are plotted in Figure 6.

The particle size distribution curves in Figure 6 show a slight alteration of the particle size distribution with water contents of $10 \mathrm{wt} . \%$ and $20 \mathrm{wt} . \%$ above $3 \mathrm{~mm}$. This suggests that the structure of the material might most likely have experienced fragmentation, material losses and a sort of cleaning effect due to complete drying, remixing, re-moisturization and a second particle size classification (i.e. sieving), since the same composite samples used to determine the particle size distribution in raw state of both batches were used for the adjusted water contents. This was the case because there were no additional virgin samples from the fine fractions available for this purpose. Nevertheless, taking into account that relevant amounts of grouped material fractions other than "Agglomerated fines $<10$ mm" (i.e. "Combustibles", "Inert", "Fe metals", "Non-Fe metals" and "Others") were not identified below a particle size of $3.15 \mathrm{~mm}$ during the material characterization of the fine fractions (Hernández Parrodi et al., 2019a), the sorting of the fine fractions into "Combustibles + Others", "Inert", "Fe metals" and "Non-Fe metals" would only make sense above $3 \mathrm{~mm}$. Thus, given that the curve for $10 \mathrm{wt} . \%$ water content could be expected to be very close to the one in dry state, it was concluded that a reduction of the original water content (median of $27 \mathrm{wt} . \%$ ) to around $15 \mathrm{wt} . \%$ would suffice to allow an adequate mechanical processing of the fine fractions above $3 \mathrm{~mm}$. The latter, assuming that the additional amount of surface defilements in comparison to dry state, which was visually determined as not quantitatively relevant, would not interfere significantly with the efficiency and effectiveness of the sensor-based sorting steps of the mechanical processing, nor to meet the quality standards of the targeted outputs (i.e. RDF, substitutes for construction aggregates and soil in construction applications, and ferrous and non-ferrous metals). Nonetheless, a further reduction of the water content might be required for adequate particle size classification below $3 \mathrm{~mm}$; especially below $0.6 \mathrm{~mm}$, where the needed reduction appears to be below $10 \mathrm{wt} . \%$.

Therefore, in order to assess the potential for material and energy recovery from the fine fractions of the MSG landfill through the selected dry mechanical processing approach, 2 scenarios with different water contents were studied and compared. These scenarios correspond to the above determined optimal water content state of $15 \mathrm{wt} . \%$ and the dry state.

\subsection{General mass balance}

In order to obtain a full overview of the mass distribution in the tested mechanical processing of the fine fractions, the outputs of the whole mechanical processing were classified into 6 categories, namely "Fine fractions $<4.5 \mathrm{~mm}$ ", "Inert", "Combustibles", "Fe metals", "Non-Fe metals" and, depending on the state, either "Material \& water losses" for the optimal water content state or "Material losses" for the dry state. The output "Fine fractions $<4.5 \mathrm{~mm}$ " in this case study corresponds to the material that was generated by a sieving step at $4.5 \mathrm{~mm}$ along the mechanical proces- 


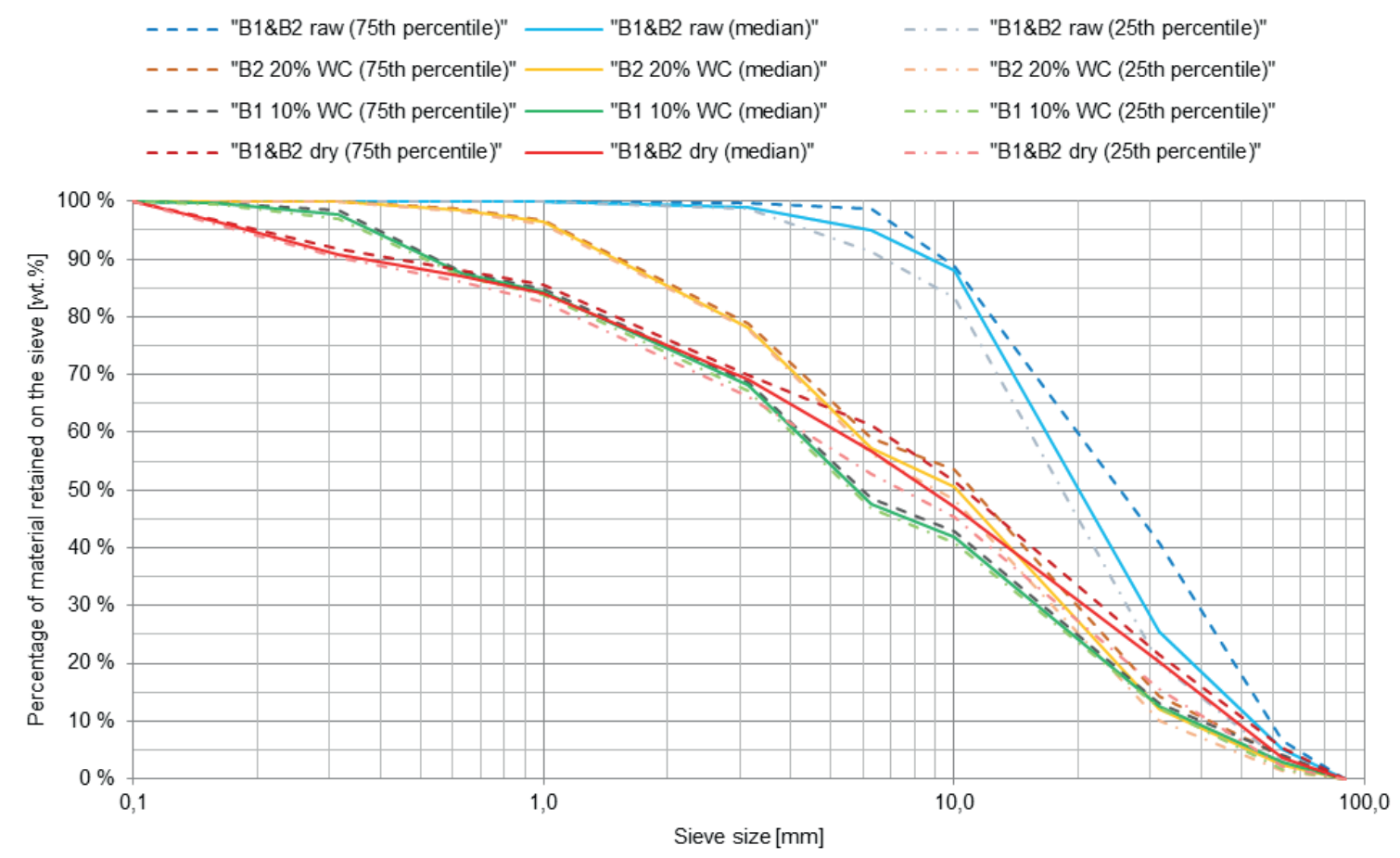

FIGURE 6: Particle size distribution of the fine fractions with different water contents.

sing, and it is referred to as "Soil-like material" concerning its apparent material composition. It is relevant to clarify that, as stated in Hernández Parrodi, Höllen, \& Pomberger, 2018b, the term "Soil-like material" does not intend to rigorously classify this material as soil, but instead employs it for reasons of appearance, as well as because it is a commonly used term in the field. The amount of each category for each composite sample was determined for each state and the median was calculated $(n=8)$. This information is displayed for each category and state in form of Sankey diagrams in Figure 7.

As shown in Figure 7, both the optimal water content state and the dry state presented the same tendency in terms of the amounts obtained from each output of the mechanical processing, in which most of the fine fractions corresponded to the "Fine fractions $<4.5 \mathrm{~mm}$ " output, with amounts of $42.9 \mathrm{wt} . \%$ and $42.7 \mathrm{wt} . \%$, respectively. That output was followed by "Inert", with amounts of $35.5 \mathrm{wt} . \%$ in the optimal water content state and $37.2 \mathrm{wt} \%$ in the dry state. "Combustibles" output followed "Inert" with the respective amounts of $12.5 \mathrm{wt} . \%$ and $9.0 \mathrm{wt} . \%$ in the optimal water content and dry states. Subsequently, "Material \& water losses" in the optimal water content state were slightly lower than "Material losses" in the dry state, with amounts of 7.6 wt.\% and 7.9 wt.\%, respectively. This may be explained by the fact that the presence of water increased the weight of certain materials to some extent and promoted the formation of surface defilements and agglomerates of fine particle sized material $(<1 \mathrm{~mm})$, which in turn decreased the loss of light and small particle sized materials (e.g. plastic foils and dust). However, it should be said that the material in the dry state might also have been influenced to a certain extent by the presence of water due to absorption/adsorption of humidity from the environment, which was not monitored throughout the whole mechanical processing nor taken into account in the mass balance of this state. Hence, the mass increase due to the influence of humidity from the environment might have compensated for a certain amount of material losses in the dry state, as well as decreased losses in the form of dust. Therefore, material losses in a strictly dry state might be higher than those reported in the present study. As for the amounts of "Fe metals" and "Non-Fe metals" outputs, a lower amount of "Fe metals" (0.9 wt.\%) was obtained in the optimal water content state with respect to the dry state (1.4 wt.\%), whilst the amount of "Non-Fe metals" obtained in the optimal water content state $(0.4 \mathrm{wt} . \%)$ was slightly larger than in the dry state $(0.3 \mathrm{wt} . \%)$. Discrepancies regarding the amounts between outputs "Fine fractions $<4.5 \mathrm{~mm}$ ", "Inert", "Combustibles", "Fe metals" and "Non-Fe metals" in the optimal water content and dry states are addressed in the following section.

\subsection{Mass balance of grouped material fractions per particle size range}

Regarding the different materials recovered from the fine fractions and, analogously to the results of the material characterization presented in Section 3.1, a mass balance of the obtained materials according to particle size range was performed using quantiles. The resulting information was organized according to the following grouped material fractions: "Combustibles", "Inert", "Fe metals", "Non-Fe metals" and "Fine fractions <4.5 mm (Soil-like material)", which are in accordance with the categories used to classify the outputs of the mechanical processing in the previous section (Section 3.2) and the particle size ranges generated along the mechanical processing (i.e. 90-30 mm, 30-10 mm and 10-4.5 mm). These grouped ma- 
(a)

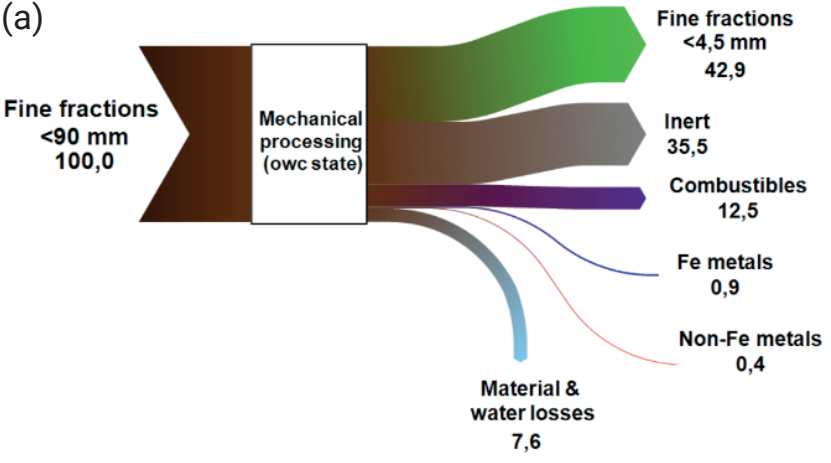

(b)

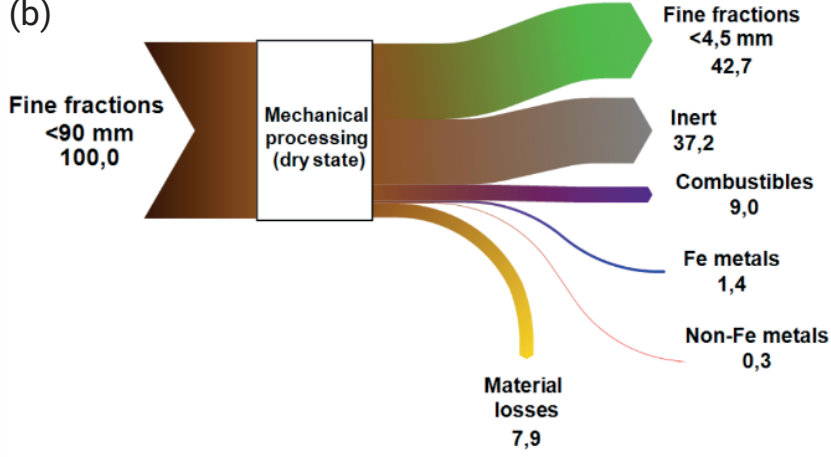

FIGURE 7: General mass balance of the mechanical processing in the a) optimal water content (owc) and b) dry states [figures in wt.\%].

terial fractions are also in agreement with those of the material characterization presented in Table 1, except for the fraction "Fine fractions $<4.5 \mathrm{~mm}$ (Soil-like material)", which has a particle size $<4.5 \mathrm{~mm}$ and, hence, corresponds partially to fraction "Fine fractions $<10 \mathrm{~mm}$ (Mixed materials)" and fraction "Others" of the material characterization, from which most part ended up in the fraction "Combustibles" of the mechanical processing due to its characteristics. Unlike material characterization, which was performed by hand down to a particle size of $10 \mathrm{~mm}$, the mechanical processing was implemented down to $4.5 \mathrm{~mm}$, since small amounts of recoverable materials were still visually identified below $10 \mathrm{~mm}$ and above $3.15 \mathrm{~mm}$ in the material characterization (Hernández Parrodi et al., 2019a). Thus, most of the fraction "Fine fractions $<10 \mathrm{~mm}$ (Mixed materials)" is composed of the "Fine fractions $<4.5 \mathrm{~mm}$ (Soil-like material)" fraction, whereas the remainder is expected to be distributed among the rest of the grouped material fractions (i.e. "Combustibles", "Inert", "Fe metals" and "Non-Fe metals") in the particle size range $10-4.5 \mathrm{~mm}$ of the mechanical processing.

The recovered amounts of each grouped material fraction according to particle size range for each state (i.e. the optimal water content and dry states) of the mechanical processing are summarized in Table 2, in which, in contrast to the rest of the figures in this article, two decimal figures were employed in order to depict the low amounts of non-Fe metals recovered from the particle size range 10$4.5 \mathrm{~mm}$.

As is the case for the general mass balance discussed in Section 3.2, figures in Table 2 show a clear common trend with respect to the amount of each grouped material

TABLE 2: Amounts of grouped material fractions per particle size range from mechanical processing.

\begin{tabular}{|c|c|c|c|c|c|c|c|}
\hline \multirow{3}{*}{\multicolumn{2}{|c|}{$\begin{array}{l}\text { Particle size range / Grouped } \\
\text { material fraction }\end{array}$}} & \multicolumn{6}{|c|}{ Amount [wt.\%] } \\
\hline & & \multicolumn{3}{|c|}{15 wt. $\%$ water content } & \multicolumn{3}{|c|}{ Dry state } \\
\hline & & \multirow{2}{*}{$\begin{array}{c}\mathbf{2 5}^{\text {th }} \text { percentile } \\
3.46\end{array}$} & \multirow{2}{*}{$\begin{array}{c}\text { Median } \\
4.64\end{array}$} & \multirow{2}{*}{$\frac{75^{\text {th }} \text { percentile }}{5.33}$} & \multirow{2}{*}{$\begin{array}{c}\mathbf{2 5}^{\text {th }} \text { percentile } \\
3.37\end{array}$} & \multirow{2}{*}{$\begin{array}{c}\text { Median } \\
4.13\end{array}$} & \multirow{2}{*}{$\frac{75^{\text {th }} \text { percentile }}{4.66}$} \\
\hline $90-30$ mm & Combustibles & & & & & & \\
\hline & Inert & 13.57 & 15.26 & 16.87 & 15.06 & 15.47 & 16.10 \\
\hline & Fe metals & 0.20 & 0.32 & 0.44 & 0.46 & 0.59 & 1.03 \\
\hline & Non-Fe metals & 0.15 & 0.21 & 0.27 & 0.12 & 0.24 & 0.34 \\
\hline & Soil-like material & 0.88 & 1.15 & 1.26 & 0.91 & 1.08 & 1.14 \\
\hline \multirow[t]{5}{*}{$30-10 \mathrm{~mm}$} & Combustibles & 4.57 & 4.96 & 6.72 & 2.34 & 2.67 & 3.16 \\
\hline & Inert & 11.93 & 15.60 & 17.17 & 12.51 & 12.97 & 14.23 \\
\hline & Fe metals & 0.26 & 0.46 & 0.55 & 0.27 & 0.38 & 0.55 \\
\hline & Non-Fe metals & 0.11 & 0.15 & 0.15 & 0.05 & 0.07 & 0.08 \\
\hline & Soil-like material & 0.79 & 0.81 & 0.87 & 1.00 & 1.28 & 1.37 \\
\hline \multirow[t]{5}{*}{$10-4.5 \mathrm{~mm}$} & Combustibles & 2.4 & 2.51 & 2.71 & 1.82 & 1.95 & 2.27 \\
\hline & Inert & 5.84 & 6.31 & 6.83 & 6.06 & 8.06 & 9.90 \\
\hline & Fe metals & 0.15 & 0.17 & 0.17 & 0.24 & 0.27 & 0.29 \\
\hline & Non-Fe metals & 0.02 & 0.02 & 0.03 & 0.02 & 0.03 & 0.03 \\
\hline & Soil-like material & 1.26 & 1.30 & 1.46 & 2.41 & 2.71 & 3.24 \\
\hline $\begin{array}{l}\text { Fine fractions } \\
<4.5 \mathrm{~mm}\end{array}$ & Soil-like material & 36.88 & 39.54 & 40.27 & 36.90 & 37.50 & 39.12 \\
\hline
\end{tabular}

Notes: Total amounts do not account for $100 \mathrm{wt}$ \% due to losses of material and water (if the case) along mechanical processing and the utilization of quantiles. 
fraction in particle size ranges $90-30 \mathrm{~mm}$ (in both states), $30-10 \mathrm{~mm}$ (in both states) and $10-4.5 \mathrm{~mm}$ (only in the optimal water content state), in which most of the material corresponded to the "Inert" fraction, followed by fractions "Combustibles", "Soil-like material", "Fe metals" and "Nonferrous metals". This information shows that the trend presented by the fine fractions at a general level (particle size range $90-4.5 \mathrm{~mm}$ ) was also valid at a more specific level (particle size ranges $90-30 \mathrm{~mm}, 30-10 \mathrm{~mm}$ and 10 $4.5 \mathrm{~mm}$ ). Nevertheless, this was the case only to a certain extent, since the same tendency was not identified in the particle size range $10-4.5 \mathrm{~mm}$ in the dry state, in which most of the material was allocated to the fraction "Inert", but, in contrast, the latter was followed by fraction "Soillike material" instead of by fraction "Combustibles". This may be the case because, in general, fractions presented a lower amount of surface defilements in the dry state, which in the case of "Combustibles" in a particle size range of 10-4.5 mm might represent a significant loss in terms of mass. However, fractions "Fe metals" and "Non-Fe metals" in the particle size range $10-4.5 \mathrm{~mm}$ maintained the same trend as particle size ranges $90-30 \mathrm{~mm}$ and $30-10 \mathrm{~mm}$.

In the optimal water content state, the particle size ranges $90-30 \mathrm{~mm}$ and $30-10 \mathrm{~mm}$ presented similar total amounts of material, with $21.6 \mathrm{wt} . \%$ and $22.0 \mathrm{wt} . \%$, respectively; whereas the particle size range $10-4.5 \mathrm{~mm}$ accounted for $10.3 \mathrm{wt} \%$. In the dry state, most of the material was present in the particle size range $90-30 \mathrm{~mm}$ with an amount of $21.5 \mathrm{wt} . \%$, followed by the particle size range 30-10 mm with 17.4 wt.\% and by $10-4.5 \mathrm{~mm}$ with $13.0 \mathrm{wt}$.\%. These figures show that the total amount of material in the dry state tended to decrease according to particle size in the particle size ranges between $90 \mathrm{~mm}$ and $4.5 \mathrm{~mm}$. Additionally, the presence of water affected the amount of the particle size range $30-10 \mathrm{~mm}$ the most, which altered such trend in the optimal water content. Nonetheless, the presence of water also affected the amount of material in the particle size ranges $90-30 \mathrm{~mm}$ and $10-4.5 \mathrm{~mm}$, although to a lesser extent; the $90-30 \mathrm{~mm}$ range was the least affected.

As for the total amounts of the grouped material fractions according to particle size range, results show that most of fractions "Combustibles", "Inert", "Fe metals" and "Non-Fe metals" was extracted from particle size ranges 90-30 $\mathrm{mm}$ and $30-10 \mathrm{~mm}$ in both states. Furthermore, the particle size range $30-10 \mathrm{~mm}$ was mostly affected by the presence of water, as the difference between the amount obtained in the dry state and the one obtained in the optimal water content state was the greatest in that particle size range. Notwithstanding, the particle size range 10$4.5 \mathrm{~mm}$ could be a relevant source of "Inert" fraction and could also be used to obtain an additional amount of "Combustibles". The amounts of "Soil-like material" increased as the particle size decreased from $90 \mathrm{~mm}$ to $4.5 \mathrm{~mm}$ in the dry state, whilst in the optimal water content state most of it was obtained in the particle size range $10-4.5 \mathrm{~mm}$, followed by particle size ranges $90-30 \mathrm{~mm}$ and $30-10 \mathrm{~mm}$. However, the fraction "Soil-like material" presented fair variations, in general, between the optimal water content and dry states, from which the highest corresponded to the particle size range $10-4.5 \mathrm{~mm}$, followed by $30-10 \mathrm{~mm}$. The grouped material fraction that showed a greater variation due to the presence of water was "Non-Fe metals" in the particle size range $30-10 \mathrm{~mm}$, which showed a significant decrease in terms of amount in the dry state. In turn, fractions "Soil-like material" and "Ferrous metals" presented a significant increase in the dry state with respect to the optimal water content state. These variations are also likely due to the greater amount of surface defilements and agglomerates in the optimal water content state, which can affect the efficiency of separation processes and affect the mass of certain materials.

The previous information shows that the presence of water affected material types and particle sizes in similar and different ways at the same time, since it can increase the mass of a certain material by absorption/adsorption and/or the presence of surface defilements. This may alter the characteristics of that material, which might play a crucial role in a certain processing step (e.g. density separation and sensor-based sorting). Simultaneously, the presence of water can promote the formation of agglomerates that affect the particle size distribution of the fine fractions, which might also play an important role in mechanical processing steps (e.g. sieving and metals separation). In addition, dust generation and material losses were also affected by the presence of water, which presented lower amounts in the optimal water content state.

Comparing the amounts obtained from each grouped material fraction of the mechanical processing in particle sizes $90-30 \mathrm{~mm}$ and $30-10 \mathrm{~mm}$ in the dry state with those of the material characterization in particle sizes $90-31.5 \mathrm{~mm}$ and $31.5-10 \mathrm{~mm}$ in Table 1 shows that there were slight deviations among the amounts of both. This might mainly be attributed to the fact that the amounts of the material characterization were the result of the manual sorting of all four batches excavated at the MSG landfill, while those of the mechanical processing were the result of processing batch 1 and batch 2 . However, such deviations are minor and, thus, it can be said that the amounts of each grouped material fraction obtained in the mechanical processing are in agreement with the expected quantities.

In order to summarize and evaluate the total obtained amount of each grouped material fraction from the fine fractions by means of the tested mechanical processing in the optimal water content and dry states, the amounts from particle size ranges $90-30 \mathrm{~mm}, 30-10 \mathrm{~mm}$ and 10 $4.5 \mathrm{~mm}$ were accumulated in a single particle size range (i.e. $90-4.5 \mathrm{~mm}$ ), while the amounts of "Soil-like material" from those particle size ranges were congregated in the grouped material fraction "Fine fractions $<4.5 \mathrm{~mm}$ (Soil-like material)". This information is displayed in Table 3.

In the optimal water content state, total amounts of 40.0-43.6 wt.\% "Soil-like material", 34.1-39.1 wt.\% "Inert", 11.8-12.9 wt.\% "Combustibles", 0.6-1.2 wt.\% "Fe metals" and 0.2-0.5 wt.\% "Non-Fe metals" were obtained. In turn, total amounts of 41.9-43.9 wt.\% "Soil-like material", 35.9-39.0 wt.\% "Inert", 7.4-10.0 wt.\% "Combustibles", 1.21.8 wt.\% "Fe metals" and 0.2-0.4 wt.\% "Non-Fe metals" were obtained in the dry state.

Generally, it can be concluded that the higher recovered amounts of "Combustibles" and "Non-Fe metals" in the 
TABLE 3: Total amounts of grouped material fractions from mechanical processing.

\begin{tabular}{|c|c|c|c|c|c|c|c|}
\hline \multirow{3}{*}{\multicolumn{2}{|c|}{$\begin{array}{l}\text { Particle size range / Grouped material } \\
\text { fraction }\end{array}$}} & \multicolumn{6}{|c|}{ Amount [wt.\%] } \\
\hline & & \multicolumn{3}{|c|}{15 wt. \% water content } & \multicolumn{3}{|c|}{ Dry state } \\
\hline & & $25^{\text {th }}$ percentile & Median & $75^{\text {th }}$ percentile & $25^{\text {th }}$ percentile & Median & $75^{\text {th }}$ percentile \\
\hline \multirow[t]{4}{*}{$90-4.5 \mathrm{~mm}$} & Combustibles & 11.8 & 12.5 & 12.9 & 7.4 & 9.0 & 10.0 \\
\hline & Inert & 34.1 & 35.5 & 39.1 & 35.9 & 37.2 & 39.0 \\
\hline & Fe metals & 0.6 & 0.9 & 1.2 & 1.2 & 1.4 & 1.8 \\
\hline & Non-Fe metals & 0.2 & 0.4 & 0.5 & 0.2 & 0.3 & 0.4 \\
\hline Fine fractions $<4.5 \mathrm{~mm}$ & Soil-like material & 40.0 & 42.9 & 43.6 & 41.9 & 42.7 & 43.9 \\
\hline
\end{tabular}

Notes: Total amounts do not account for $100 \mathrm{wt}$ \% due to losses of material and water (if the case) along mechanical processing and the utilization of quantiles.

optimal water content state with respect to the dry state can be attributed to the absorption/adsorption of water by some of the materials present in those fractions, such as textiles and leather in the "Combustibles" fraction and "Fine fractions $<4.5 \mathrm{~mm}$ (Soil-like material)" in the form of surface defilements and impurities in both fractions, rather than to a better performance of the mechanical processing in the optimal water content state. Controversially, almost equal amounts of "Fine fractions $<4.5 \mathrm{~mm}$ (Soil-like material)" were obtained in both states, while a lower amount of that fraction would have been expected in the optimal water content. This was likely the case because most of the water was absorbed/adsorbed by the "Fine fractions $<4.5 \mathrm{~mm}$ (Soil-like material)" fraction, which compensated for the amount of the latter lost to the "Combustibles", "Inert", "Fe metals" and "Non-Fe metals" fractions in the optimal water content state. In addition, a larger amount of "Inert" was obtained in the dry state than in the optimal water content state, which may also be explained by the influence of water in all fractions in the optimal water content state. Moreover, results suggest that the recovery of "Fe metals" can be increased by processing the material in the dry state, while the quality of the recovered "Non-Fe metals" can be improved in the same manner.

Furthermore, it can be said that the results from the mechanical processing in both states are in agreement with the total amounts of the material characterization of the fine fractions obtained by Hernández Parrodi et al., 2019a, in dry state: in that study amounts in the ranges of 37.8-55.6 wt.\% "Fine fractions < 10 mm (Mixed materials)", 31.1-35.4 wt.\% "Inert", 2.1-19.7 wt.\% "Combustibles", 3.3-4.2 wt.\% "Agglomerated fines <10 mm", 0.6-3.4 wt.\% "Others" and 0.6-1.8 wt.\% "Total metals" were reported. One should take into account the following considerations: i) the fine fractions were segregated to a greater extent in the mechanical processing than in the material characterization (i.e. $4.5 \mathrm{~mm}$ vs. $10 \mathrm{~mm}$, respectively), ii) most of the fraction "Others" of the material characterization is expected to be distributed among the fractions "Combustibles" and "Inert" of the mechanical processing, iii) most of the fraction "Agglomerated fines $<10 \mathrm{~mm}$ " of the material characterization is expected to be in the fraction "Inert" of the mechanical processing, iv) material losses were greater in the mechanical processing than in the material characterization (i.e. ca. 8 wt.\% vs. $<2$ wt.\%, respectively), v) amounts of surface defilements and agglomerates were most likely affected by the fact that the same composite samples were used firstly for the material characterization and secondly for the mechanical processing, and vi) the results of the material characterization take into account the 4 excavated batches at the MSG landfill, while the material processing was performed with 2 batches. Moreover, it is relevant to highlight that an additional total amount of over $10 \mathrm{wt} . \%$, distributed among grouped material fractions "Combustibles", "Inert", "Fe metals" and "Non-Fe metals", could be obtained in both states by processing the fine fractions down to a particle size of $4.5 \mathrm{~mm}$.

The results of the mechanical processing in the optimal water content state (water content of ca. 15 wt.\%) were not compared to those of the material characterization in raw state (water content of ca. 27 wt.\%) due to significant differences in water content. Furthermore, the optimal water content state is considered as an alternative to process the fine fractions in dry state with lower energy demand, material loss and dust emissions. Therefore, the mechanical processing tested in this study can be regarded as a successful approach to separate the fine fractions into sub-fractions in an effective and efficient manner, which facilitate WtM and WtE schemes. Nevertheless, this is to be verified by means of laboratory analysis as a next step.

\subsection{Physical appearance of output fractions}

In order to document and discuss the physical appearance of all grouped material fractions obtained from the tested mechanical processing, photographs of each output fraction in both the optimal water content and dry states were taken on a grid of $1 \mathrm{~cm}$ per $1 \mathrm{~cm}$. Figure 8 displays pictures of the grouped material fractions "Combustibles", "Inert", "Fe metals" and "Non-Fe metals" obtained in the optimal water content state, while images of the same fractions obtained in the dry state are shown in Figure 9.

The comparison of the images in Figure 8 to those in Figure 9 shows that the recovered grouped material fractions "Combustibles", "Inert", "Fe metals" and "Non-Fe metals" presented a greater amount of surface defilements and agglomerates (i.e. impurities), both mainly composed of fraction "Fine fractions $<4.5 \mathrm{~mm}$ (Soil-like material)", in the optimal water content state than in the dry state. This could be remediated by the implementation of one or se- 


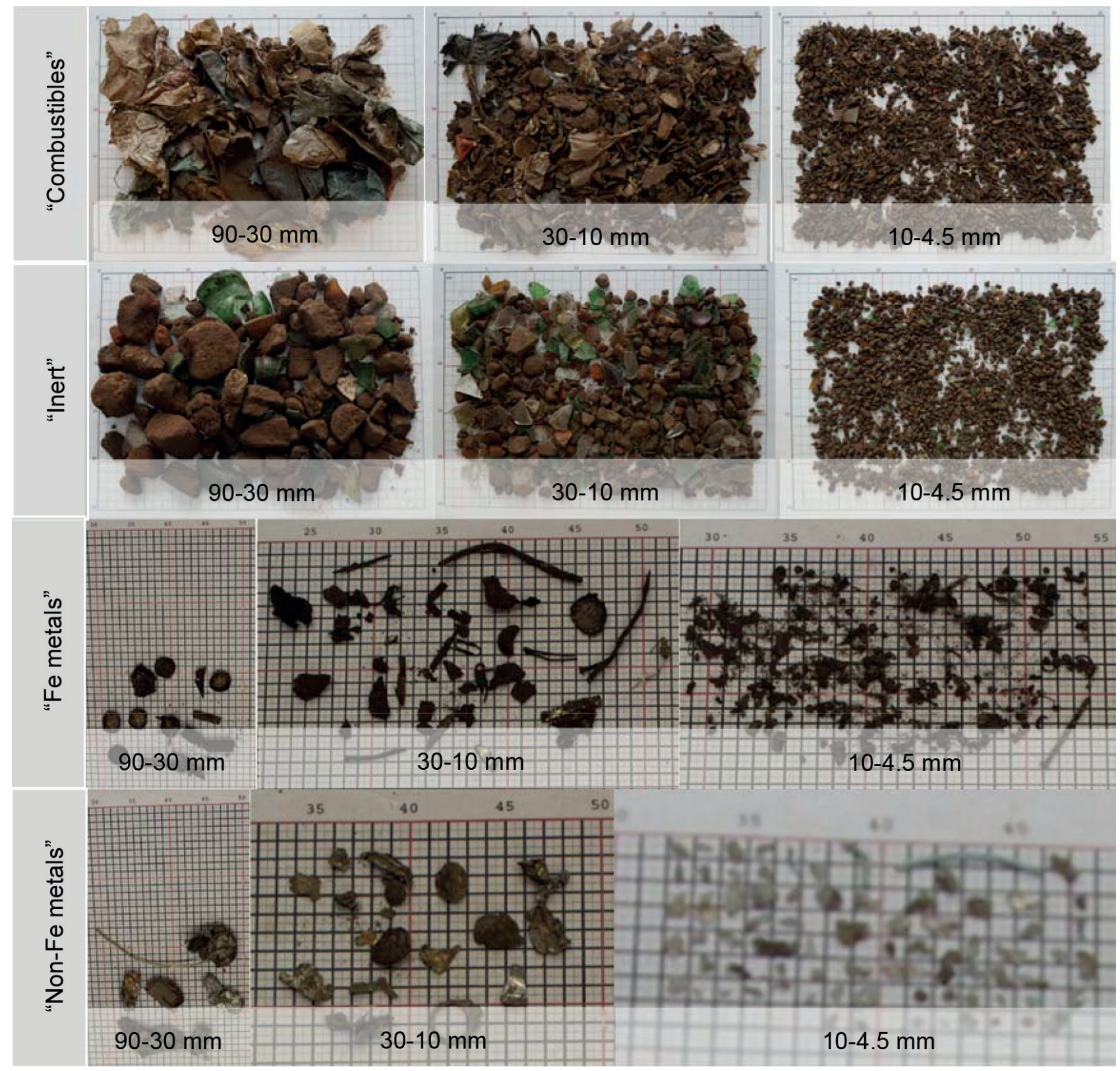

FIGURE 8: Grouped material fractions recovered in the optimal water content state.

veral washing steps, which could significantly reduce the amount of impurities (Tameda et al., 2018) in those fractions. However, the effectiveness of the mechanical processing in terms of its capability to separate the material throughput into the different grouped material fractions did not seem to be greatly affected, since there was no significant discrepancy of materials present in an incorrect grouped material fraction between both the optimal water content state and the dry state.

Regarding the physical appearance of fraction "Fine fraction $<4.5 \mathrm{~mm}$ (Soil-like material)" in the optimal water content and dry states, Figure 10 shows that its visual characteristics did not differ significantly between both states. Nonetheless, a greater amount of agglomerated material $<1 \mathrm{~mm}$ could be expected in the optimal water content state and, therefore, a reduction of the water content would be necessary for an adequate further dry mechanical processing of this fraction.

It is important to reiterate that laboratory analysis of the fractions "Combustibles", "Inert" and "Fine fractions $<4.5 \mathrm{~mm}$ (Soil-like material)" are to follow the present stu$\mathrm{dy}$, in order to determine quantitatively if the applicable specifications for the foreseen purposes have been met by either one or both states, and therefore it cannot be yet assured, that the obtained outputs can be subject to valorization schemes of WtM and WtE.

\section{CONCLUSIONS}

In this study total amounts of 40.0-43.6 wt.\% "Fine fractions <4.5 mm (Soil-like material)", 34.1-39.1 wt.\% "Inert", 11.8-12.9 wt.\% "Combustibles", 0.6-1.2 wt.\% "Fe metals" 


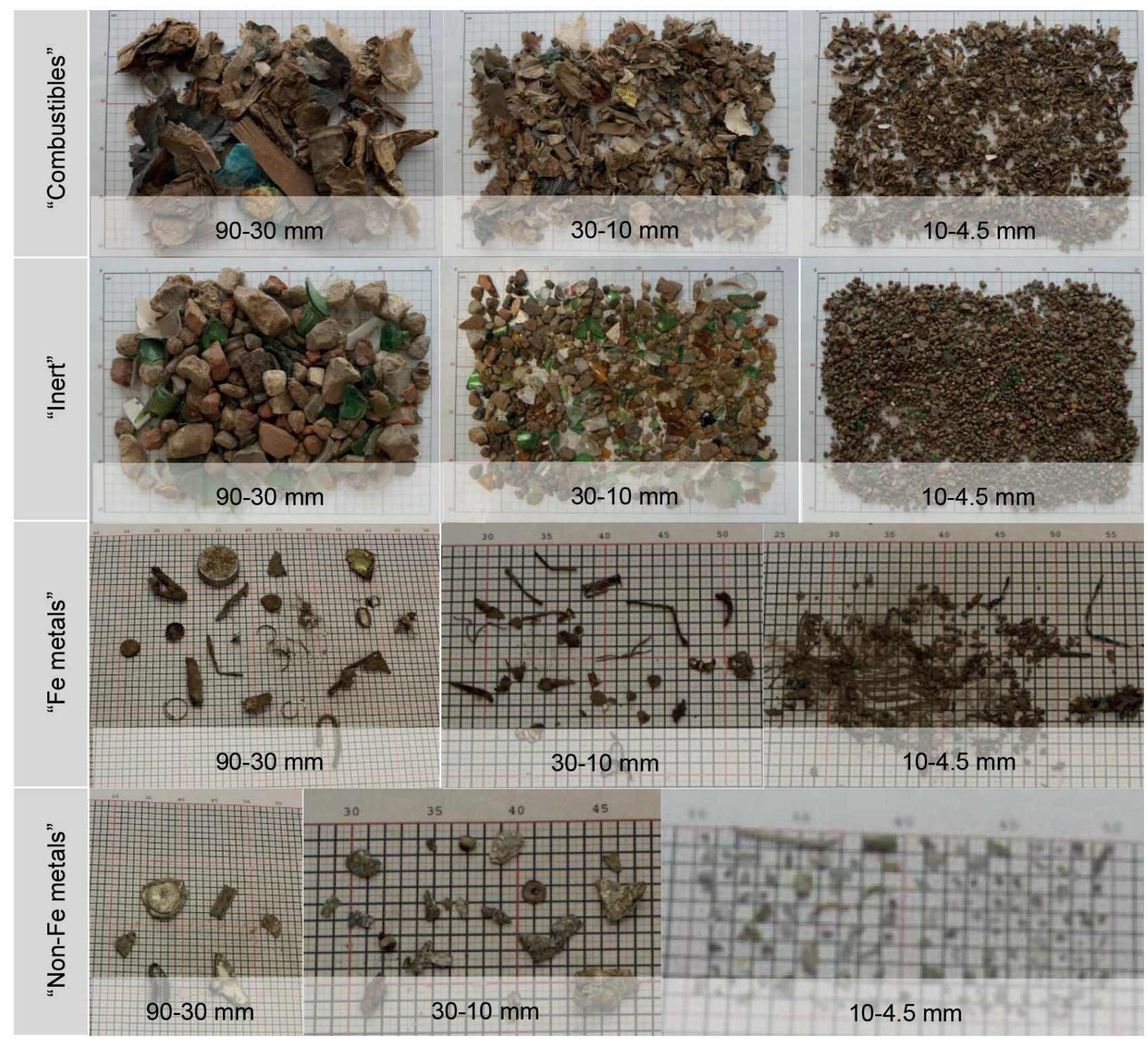

FIGURE 9: Grouped material fractions recovered in the dry state.

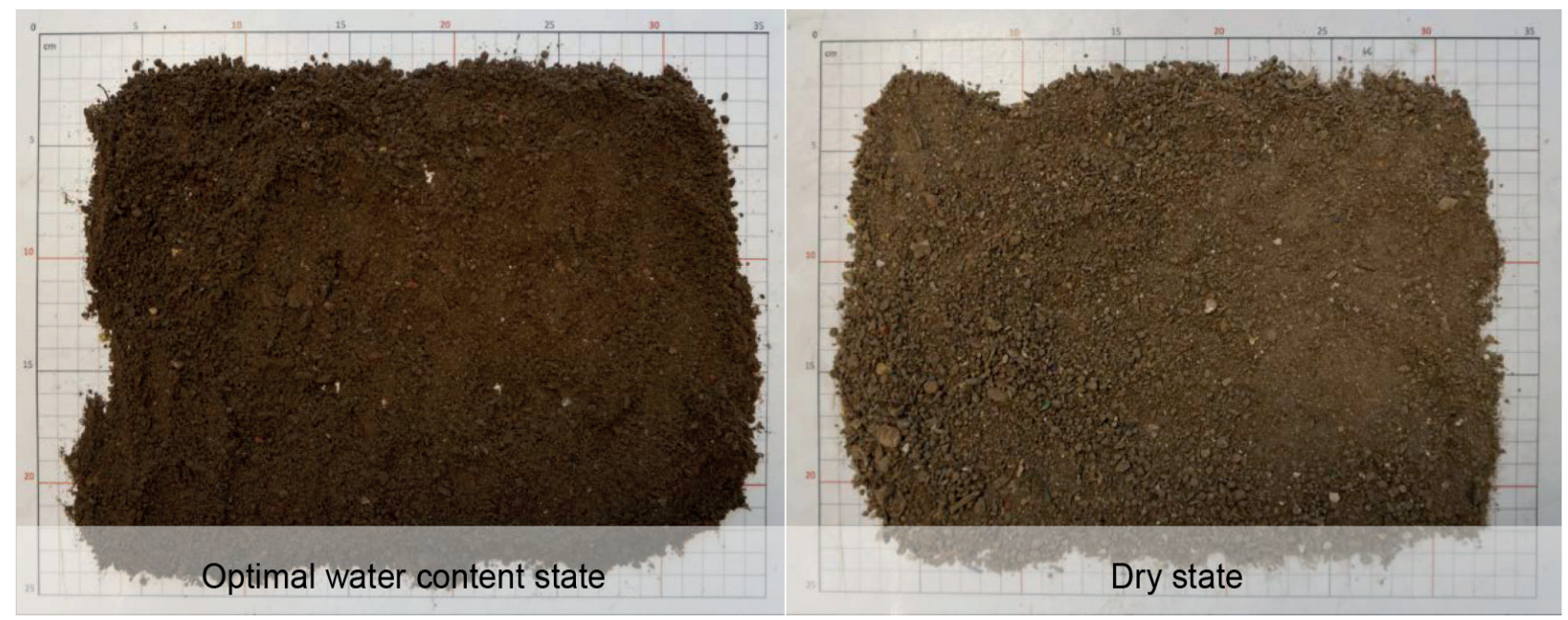

FIGURE 10: "Soil-like material" fraction in the optimal water content and dry states. 
and 0.2-0.5 wt.\% "Non-Fe metals" were obtained in the optimal water content state, while amounts of $41.9-43.9$ wt.\% "Fine fractions $<4.5 \mathrm{~mm}$ (Soil-like material)", 35.9-39.0 wt.\% "Inert", 7.4-10.0 wt.\% "Combustibles", 1.2-1.8 wt.\% "Fe metals" and 0.2-0.4 wt.\% "Non-Fe metals" were generated in the dry state. These figures agree with the amounts determined in the material characterization of the fine fractions. Hence, it can be stated that the tested mechanical processing succeeded in sorting the fine fractions into the targeted grouped material fractions in an effective and efficient manner. Additionally, results suggest that a significant total amount of the fine fractions could be recovered through the implemented mechanical processing approach, which might contribute to the overall economic and environmental feasibility of the project in case of implementing full scale (E)LFM at the MSG landfill.

In general, the grouped material fractions recovered in the optimal water content state presented a higher amount of surface defilements and agglomerates (i.e. impurities) than in the dry state, from which fractions "Fe metals" and "Combustibles" seemed to be the most affected. Particle size range $30-10 \mathrm{~mm}$ appeared to be the most affected by the presence of water, while particle size range $90-30 \mathrm{~mm}$ was least affected. Dust generation and material losses were also influenced by the presence of water, which presented a slightly lower amount in the optimal water content state than in the dry state. Particle size ranges $90-30 \mathrm{~mm}$ and $30-10 \mathrm{~mm}$ yielded most of the recovered material, and particle size range $10-4.5 \mathrm{~mm}$ could be a relevant source of "Inert" fraction, as well as provide an additional amount of "Combustibles". A total amount of over 10 wt.\%, distributed among all grouped material fractions of particle size range 10-4.5 mm, was additionally obtained by processing the fine fractions until a particle size of $4.5 \mathrm{~mm}$.

It can be concluded that the real amounts of each grouped material fraction to be recovered from the fine fractions correspond to those obtained in the dry state, as well as the real material distribution according to particle size range. Discrepancies between the amounts obtained in the optimal water content and dry states can be mainly attributed to absorption/adsorption of water by the different types of materials present in each grouped material fraction. Additionally, these discrepancies can be due to the presence of surface defilements and agglomerates among the different grouped material fractions and particle size ranges, which in turn can affect the properties of certain materials (e.g. shape, mass and density), as well as the performance of sorting processes (e.g. particle size and density classification, magnetic and eddy-current separation and sensor-based sorting). The presence of impurities can also decrease the quality of certain materials, since they can be associated with the presence of heavy metals and organic pollutants. This could undermine the potential for the valorization of such materials in WtM and WtE schemes. However, discrepancies between both the optimal water content and dry states in this study were found to be negligible with respect to the success of the mechanical processing to separate the fine fractions into the different grouped material fractions. Nevertheless, laboratory analyses are yet to be performed in order to evaluate the effects, in terms of quality, of the greater amount of impurities present in the fractions obtained in the optimal water content state than those in the dry state. Moreover, laboratory analysis of outputs "Combustibles", "Inert" and "Fine fractions $<4.5 \mathrm{~mm}$ (Soil-like material)" will determine if these fractions can be used for the intended purposes (i.e. alternative fuel, substitute for construction aggregates and substitute for soil in construction applications, respectively) or if further treatment might be necessary.

It is important to note that the mechanical processing approach tested in this study was carried out by means of small- and pilot-scale equipment, and results may differ substantially in large-scale machinery. Furthermore, the results of this study are case specific and much attention must be paid to several factors when transposing this information for the purposes of future investigations and full-scale applications. Moreover, it is worth stressing that the current market value of secondary raw materials, such as substitutes for construction aggregates and soil in construction applications, can be very low or even have negative values, as is the case with RDF in some countries. Additionally, the extent of the mechanical processing of the fine fractions is directly proportional to its cost and highly concatenated with the quality of its outputs. Besides, usually most of the landfill-mined material corresponds to fine fractions and, hence, they can hardly be left out of the scope of (E)LFM projects. Therefore, the profitability of (E) LFM is directly linked to a successful recovery of materials and energy from the fine fractions. Hence, the mechanical processing of the fine fractions is to be designed in such an optimal way that the applicable quality standards of the desired outputs can be met, and capital and operational expenditures do not hinder the viability of the whole project.

\section{AKNOWLED GEMENTS}

This research has been funded by the European Union's Horizon 2020 research and innovation programme under the Marie Skłodowska-Curie grant agreement No. 721185 "NEW-MINE" (EU Training Network for Resource Recovery through Enhanced Landfill Mining; www. new-mine.eu). The authors wish to express their special gratitude to Renewi Belgium SA/NV, Stadler Anlagenbau $\mathrm{GmbH}$, Department of Processing and Recycling (IAR) of the RWTH Aachen University and Chair of Waste Processing Technologies and Waste Management (AVAW) of the Montanuniversität Leoben for their straightforward collaboration and support.

\section{REFERENCES}

Bunge, R. (2012). Mechanische Aufbereitung: Primär- und Sekundärrohstoffe. Germany: Wiley-VCH.

Bureau d'études greisch (beg) (2002). Centre d'Enfouissement Technique de Mont-Saint-Guibert: Etude des conséquences de l'octroi du permis d'urbanisme du 29.10.01 sur les conditions d'exploitation du permis du 16.12.98.

Burlakovs, J., Kriipsalu, M., Porshnov, D., Jani, Y., Ozols, V., Pehme, K.M., et al. (2019). Gateway of Landfilled Plastic Waste Towards Circular Economy in Europe. Separations, 6(2), 25.

García López, C., Ni, A., Hernández Parrodi, J. C., Küppers, B., Raulf, K., \& Pretz, T. (2019). Characterization of landfill mining material after ballistic separation to evaluate material and energy recovery potential. Detritus, 8(1), 5-23. 
Hernández Parrodi, J. C., Höllen, D., \& Pomberger, R. (2018a). Characterization of fine fractions from landfill mining: A review of previous investigations. Detritus, 2(1), 46-62.

Hernández Parrodi, J. C., Höllen, D., \& Pomberger, R. (2018b). Potential and main technological challenges for material and energy recovery from fine fractions of landfill mining: A critical review. Detritus, 3(1), 19-29.

Hernández Parrodi, J. C., García López, C., Küppers, B., Raulf, K., VolIprecht, D., Pretz, T., \& Pomberger, R. (2019a). Case study on enhanced landfill mining at Mont-Saint-Guibert landfill in Belgium: Characterization and potential of fine fractions. Detritus, 8(1), 47-61.

Hernández Parrodi, J. C., Lucas, H., Gigantino, M., Sauve, G., Esguerra, J. L., Einhäupl, P., et al. (2019b). Integration of resource recovery into current waste management through (enhanced) landfill mining. Detritus, 8(1), 141-156

Jones, P. T., Geysen, D., Rossy, A., \& Bienge, K. (2010). Enhanced Landfill Mining (ELFM) and Enhanced Waste Management (EWM): essential components for the transition to Sustainable Materials Management (SMM). Proceedings of the 1st International Academic Symposium on Enhanced Landfill Mining. 4-6 October, 2010. Houthalen-Helchteren, Belgium.
Küppers, B., Hernández Parrodi, J. C., García López, C., Pomberger, R., \& Vollprecht, D. (2019). Potential of sensor-based sorting in enhanced landfill mining. Detritus, 8(1), 24-30.

Lucas, H., García López, C., Hernández Parrodi, J. C., Vollprecht, D., Raulf, K., Pomberger, R., et al. (2019). Quality assessment of non-ferrous metals in landfill mining: A caste study in Belgium. Detritus, 8(1), 79-90.

Tameda, K., Hanashima, M., Lee, N.-h., Cho, E.-a., Kawashimaf, M., \& Higuchi, S. (2018). Recycling of waste plastics disposed of in landfills: The effect of washing treatment. Detritus, 1(1), 102-109.

Van Vossen, W. J., \& Prent, O. J. (2011). Feasibility study: Sustainable material and energy recovery from landfills in Europe. Proceedings Sardinia 2011. Thirteenth International Waste Management and Landfill Symposium. 3-7 October 2011. S. Margherita di Pula, Cagliari, Italy, 247-248.

Wagner, T. P., \& Raymond, T. (2015). Landfill mining: Case study of a successful metals recovery project. Waste Management, 45, 448457.

Winterstetter, A., Laner, D., Rechberger, H., \& Fellner, J. (2015). Framework for the evaluation of anthropogenic resources: A landfill mining case study - Resource or reserve? Resources, Conservation and Recycling, 96, 19-30. 